\title{
Isócrates y los orígenes de la educación cívica. Actualidad de un pensador clásico
}

Isocrates and the origin of civic education. Validity of a classical author

\author{
José Fernández-Santillán /jfsantillan@itesm.mx \\ Tecnológico de Monterrey, Campus Ciudad de México, México
}

\begin{abstract}
Isocrates has been neglect as one of the main figures of the main political thought. This essay tries his philosophical legacy, particularly his work as civic educator. Today it is necessary because it is indispensable to construct citizenship.

His method in order to promote democracy was public deliberation not only to verbal discussion but also to the diffusion of his writings. Isocrates promoted the creation of public spaces in which the deliberation was possible. That is why he is consider a contributor of the "public spaces" as we know it today.

What we underline is that Isocrates believed in the value of the word as the main transformation of the man and the political regimes. The democracy that he had in mind was the regime set up by Solon and Clistenes. He always took into account this model in order to restore the civic life in Athens and the good government in the political communities in Greece. Isocrates was enemy of the barbarians and demagogues.
\end{abstract}

Key words: civic education, policy, democracy, oligarchy, citizenship.

Resumen: Isócrates ha sido descuidado como una figura señera entre los grandes pensadores políticos de la Grecia antigua. El presente ensayo rescata el legado de este filósofo, particularmente su trabajo como educador cívico, hoy tan necesario para construir ciudadanía.

El método que utilizó para promover la democracia fue la deliberación pública, no solamente a través de la discusión verbal sino también de la difusión de escritos. En consecuencia, Isócrates contribuyó a crear espacios de discusión muy semejantes a lo que ahora conocemos como "esfera pública".

Lo que ponemos de relieve es que Isócrates creyó en el papel de la palabra como eje transformador tanto de los hombres como del régimen político. El ideal de democracia que tuvo en mente fue el régimen instaurado por Solón y Clístenes. Siempre tuvo en cuenta ese modelo para restaurar la vida cívica en Atenas y en las ciudades Estado de la Grecia antigua.

Palabra clave: educación cívica, política, democracia, oligarquía, ciudadanía. 


\section{Introducción}

El concepto "educación cívica" ha captado crecientemente el interés de los especialistas en la teoría política, pero también de los promotores de la llamada cultura cívica (gobiernos y partidos). Obviamente, se han escrito muchísimas obras al respecto comenzando por el libro clásico de Gabriel Almond y Sidney Verba (1989: 374).

Frente a un concepto de esta naturaleza, como tantos otros del lenguaje político, la atención se remite inmediatamente a las raíces históricas; es decir, a los griegos y, en especial, a Aristóteles. Como dicen dos especialistas en la materia: "Entre los griegos que escribieron sobre cuestiones políticas, es Aristóteles a quien parece haberle tocado la parte del león en lo que se refiere a la atención recibida" (Poulakos y Depew, 2004: 1).

Incluso, a El Estagirita se le atribuye, además de ser el principal escritor político griego, el papel de educador cívico. No obstante, hay estudios que reportan otros resultados: "Isócrates fue una figura de muy alto nivel en la educación cívica, en cuanto a la capacidad de discusión retórica se refiere. Mucho más que Aristóteles" (Poulakos y Depew, 2004: 2). Esta es una aseveración sustentada en un trabajo de investigación serio: Isócrates es más importante que Aristóteles en lo que se refiere a la educación cívica. Aseveración respaldada por diversos analistas como A. E. Raubitschek, quien afirma que la técnica educativa y de retórica de Isócrates fue retomada y transmitida por Cicerón (Collier's Enciclopedia, 1993: 319-320).

Isócrates vivió muchos años (436 a.C.-338 a.C.). En consecuencia, le tocó ser testigo de muchos acontecimientos: el enfrentamiento de griegos y persas, la rivalidad entre las ciudades griegas y, por si faltara algo, convulsiones a granel en su ciudad natal, Atenas. Hubo dos propósitos fundamentales que lo movió a actuar en la vida pública: restaurar la grandeza ateniense y unir a las ciudades griegas para enfrentar al enemigo común, los persas. Para lograr estos cometidos consideró que se debía recurrir al poder que caracterizó a su ciudad, la cultura. Era imperativo regresar a las bases que hicieron famosa a esa polis El instrumento privilegiado debía ser la educación.

El método que Isócrates utilizó para desarrollar su proyecto educativo fue el de los escritos de difusión en cuanto "filosofía deliberativa" (Raubitschek, 1992: 319). La deliberación como arte de la educación. Isócrates promovió el intercambio de ideas mediante la polémica; descubrió que la discusión era un método efectivo para educar al pueblo y a las élites. Por eso sus escritos cobraron nuevos bríos en la Italia renacentista. La idea fue recuperar el principio de contradicción mediante la discusión de ideas. Ese principio de contradicción, 
de hecho, es uno de los pilares de la modernidad. John Milton fue el pensador que atrajo para la era moderna el legado de Isócrates.

Como se puede deducir fácilmente, la discusión pública no puede llevarse a cabo si no está respaldada y fundamentada en la libertad individual para expresar sin cortapisas lo que cada quien colige y para publicar aquello que se juzgue conveniente. Los derechos de expresión y de imprenta, efectivamente, tienen una deuda tanto con Isócrates como con John Milton.

No es casualidad que estos autores - por distantes que sean en el tiempo- sean precursores de lo que hoy se conoce como "espacio público"; es decir, el lugar donde se discute sobre temas de interés general.

Ambos, Isócrates y Milton, pusieron por delante las razones en lugar de la fuerza. El punto crucial para mejorar a una sociedad es la educación y, en especial, la educación cívica como vía para recuperar y fortalecer a la democracia.

Lo que en este ensayo se pone de manifiesto es que Isócrates fue un defensor apasionado de la democracia. Como vivió en los tiempos en que ésta decaía, le dolió ver a Atenas hundida en la degradación; sumida en ambiciones personales y en el apetito insaciable de riquezas materiales. Muy otro había sido el espíritu con que se construyó la grandeza ateniense en la época de Solón y Clístenes; es decir, cuando Atenas estuvo llena de virtudes que fueron ejemplo para otras ciudades helénicas.

Lo que hizo Isócrates, con el afán de levantar de la postración a su ciudad, fue presentar el contraste entre la democracia ideal (esa de Solón y Clístenes) y el remedo de democracia que tenía ante sus ojos. La solución, a su parecer, consistía en reeducar a los gobernantes y gobernados: recuperar el antiguo espíritu de sacrificio, la virtud, para bien de la ciudad y dejar en un segundo plano los intereses personales.

Perfeccionó el arte de la retórica como mecanismo para difundir sus ideas de manera verbal y escrita. Al provocar la polémica dio origen a lo que hoy conocemos como "opinión pública". Escuchar lo que otros dicen y responder a esos dichos. Generar una dinámica didáctica en la que todos participen en paridad de circunstancias. Lo importante era tener como punto guía el interés general.

Ahora bien, respecto al problema del panhelenismo, éste no se jugaba tan sólo en lo que hoy se podrían llamar "las relaciones internacionales"; es decir, a nivel externo entre los Estados, sino a nivel interno, en la manera como se gobernaban, precisamente, en el seno de las ciudades-Estado. Cada potencia, ese decir, por un lado Esparta y, por otro, Atenas, trataba de intervenir en la política interior de los Estados dominados por la otra potencia promoviendo el régimen político que le era propio. Esparta promovía la oligarquía en tanto que Atenas impulsaba la democracia. 
En tales circunstancias, un punto fundamental fue la promoción del buen gobierno democrático como subordinación a la ley, la honestidad, la formación de una conciencia cívica, el respeto por los bienes ajenos, la rendición de cuentas, la sobriedad en las costumbres y, particularmente, la retórica como el arte de saber expresarse en público, la educación de la niñez y la juventud en los deportes y en la filosofía.

Las obras de Isócrates llenan todos los requisitos para ser enlistadas dentro de los grandes libros de filosofía política y de educación. Es nuestro deber no dejarlo en el abandono. Sobre todo porque fijó el propósito de que la democracia no degenerara en manos ni de los bárbaros (persas), a nivel internacional, ni de los demagogos, a nivel interno (la tiranía).

\section{El vínculo entre la Antigüedad y la Modernidad}

Quien tomó la estafeta de Isócrates y la transmitió, justamente, a la edad moderna fue John Milton en su famoso escrito Areopagitica (1644). Frente al ordenamiento emitido por el Parlamento (Licensing Order, 1643) que dispuso la previa autorización del gobierno para publicar cualquier texto, Milton reivindicó la libertad de pensamiento y la libertad de expresión:

Quien a un hombre mata quita la vida a una criatura racional, imagen de Dios; pero quien destruye un libro, mata la razón misma, mata la imagen de Dios, como si dijéramos por el ojo. Hartos los hombres no pasan de carga para el suelo; pero un buen libro es preciada vitalísima sangre de un espíritu magistral, adrede embalsamada y atesorada para un vivir más duradero que la vida (Milton, 2005: 23).

En opinión de Milton, la libertad de palabra no podía ser objeto de censura; era un agravio no sólo contra los hombres, sino especialmente contra el Padre Eterno.

En referencia a Isócrates, Milton (2005: 21) escribe:

Podría citar a quien desde su privada estancia aquel discurso escribiera a la asamblea ateniense para persuadirla de que mudara la forma de democracia a la sazón establecida. Y tal honor se pagaba en aquellas edades a quienes profesaban el estudio de la sabiduría y la elocuencia, y ello no sólo en su país, sino en tierra extraña, que urbes y señoríos gozosamente les escuchaban, y con notable respeto, al manifestarse ellos públicamente en vena de admonición al Estado.

Inspirándose en Isócrates, Milton pedía que el Estado inglés respetara la pluralidad de opiniones y no censurara la publicación de los libros. La práctica prohibitiva — continuaba su argumentación - era propia de la Inquisición.

Dios había dotado al hombre de la razón para que la usara en todos los campos; ninguna autoridad debía oponerse a ese principio. Ventilar las 
opiniones era provechoso para la comunidad política, pues nutría la unidad en torno a valores compartidos como la tolerancia. En consecuencia, debía darse prioridad al consenso construido por medio del intercambio de pareceres. La unidad política sería vana si tan sólo estuviese cimentada en la fuerza. Abundando en su argumentación, Milton (2005: 57-58) pidió a la representación política inglesa tomar en consideración el poder cultural de Inglaterra:

Lores y Comunes de Inglaterra, considerad de qué nación sois, qué nación gobernáis; no es ella opaca y obtusa sino de espíritu vivo, ingenioso y penetrante, para la invención aguda, en el discurso recia a la vez que sutil, no de tema alguno descalzada, ni del más cimero sobre el que pueda cernerse la criatura humana. Así los estudios del saber en sus ciencias más profundas fueron tan antiguos entre nosotros, y descollados, que escritores de buena antigüedad y juicio competentísimo anduvieron persuadidos de que aun la escuela de Pitágoras y la sabiduría persa arrancaron en sus comienzos de la añeja filosofía de esta isla. Y ese cuerdo y civil romano, Julio Agrícola, que aquí una vez gobernara por el César, prefería los naturales ingenios de Britania a los forzados estudios de los galos. Ni es por vano antojo que los graves y frugales transilvanos envían todos los años, tan lejos de los confines montañosos de Rusia, y más allá de los páramos hercinios, no su mocedad, sino sus hombres hechos, para que aprendan nuestro lenguaje y nuestro arte teológico.

La ordenanza emitida (Licensing Order) por el Parlamento era perjudicial por, al menos, dos motivos: esa ordenanza iba en contra de la política interior porque provocaría descontento y disturbios; pero también obraban en detrimento de la política exterior, porque Inglaterra dejaría de ejercer su influencia cultural en otras naciones.

Es curioso y significativo que, a semejanza de Isócrates, Milton ideara su alegato a manera de escrito dirigido, en primera instancia, a una asamblea, pero también tenía la intención de influir en un público más amplio. Deseaba que las ideas plasmadas en su alegato se discutieran ampliamente y se tomaran medidas para evitar las repercusiones negativas.

La Areopagitica de John Milton ha pasado a la historia como una defensa de los modernos derechos civiles. Para llevar a cabo esta defensa, Milton recuperó el legado de los griegos, y en especial de Isócrates. Milton recogió de Isócrates el arte de educar y educarse a través de la razón. De hecho, ese es el método que se sigue utilizando hoy en día en los salones de clase. Debemos a Isócrates el arte de la retórica como método educativo.

Por eso decimos que él abrió espacios de discusión que hoy llamamos esfera pública: "Su compromiso para sostener a la cultura ateniense en medio de los cambios políticos y económicos -y la creciente separación de la identidad individual y política- se parece a la moderna idea de la esfera pública"(Hariman, 2004: 227). 
Isócrates fomentó la discusión pública no sólo mediante el intercambio verbal; también lo hizo de manera literaria:

La participación de los ciudadanos en los asuntos de la polis ya no necesitaron ser pensados exclusivamente como el hablar ante una masa inflamada o indiferente según fuese el caso, reunida para escuchar las demandas contingentes de una situación particular.

La deliberación política también pudo estar compuesta por cosas escritas, hechas circular para un público lector y, en consecuencia, diseminada para una audiencia más amplia. Si fue posible participar en los asuntos de la polis dando un paso atrás y tomando distancia de la asamblea, entonces podremos ver esa distancia y ese paso como la creación de un nuevo espacio que transforma la deliberación política. Y, como resultado, pone en acto nociones alternativas de educación cívica (Enciclopedia Salvat, 1971: 1871).

Debemos tener presente que Grecia ha pasado a la historia como la fundadora de la discusión verbal. En su libro La transformación estructural de la esfera pública, Habermas (1998: 3) deja establecida la fuente histórica del concepto "esfera pública":

Aquí estamos tratando con una categoría griega transmitida a nosotros por Roma. Al llegar al más alto desarrollo de las ciudades-Estado en Grecia la esfera de la polis, que fue lo común (koiné) para los ciudadanos libres, fue separada claramente de la esfera de la oikos; en esta esfera cada individuo se remite a su propia intimidad (idia) [...] La esfera pública se configuró en la discusión (lexis), que pudo asumir, por ejemplo, la forma de consulta o plasmada en la formación de la ley así como en el terreno de las acciones comunes (praxis) la guerra o las competencias atléticas.

Lo que no se ha resaltado suficientemente es que Grecia también es la fundadora de la deliberación política escrita. Isócrates y sus obras son prueba de que los atisbos del espacio público literario también estuvieron presentes en Atenas (Poulakos y Depew, 2004: 7-9).

Isócrates creyó en el valor de la palabra hablada y escrita y en su capacidad transformadora: "promover la solidaridad política entre los griegos mediante la creación de un foro en el que hubiese un franco y honesto criticismo y la expresión libre de ideas. Más discursos filosóficos y científicos (technikos) quizá pudiese superar los reclamos retóricos a los prejuicios" (Konstan, 2004: 120). La palabra debería ser portadora de la razón, no de las pasiones para que esa transformación mejorara a las personas y a la vida colectiva.

\section{Isócrates y su tiempo}

Las fechas de nacimiento y muerte de Isócrates (436 a.C.-338 a.C.) dan testimonio, al mismo tiempo, de una vida longeva y de una época de tremendas convulsiones tanto de su ciudad natal, Atenas, como de conflictos entre las 
ciudades-Estado de Grecia. Debemos añadir que en la etapa inmediatamente anterior a su nacimiento se registraron las guerras Médicas (492 a.C.-449 a.C.).

Estos conflictos fueron, precisamente, entre el imperio Persa y las ciudades-Estado de la Hélade (como los griegos realmente llamaban a lo que hoy conocemos como Grecia) comandados por los espartanos y los atenienses unidos en la liga Panhelénica. La Primera Guerra Médica (492 a.C.-490 a.C.) comenzó con la invasión de los persas encabezada por el rey Darío contra algunas ciudades griegas.

Este primer conflicto terminó con la victoria de los helenos. La Segunda Guerra Médica (480 a.C.-478 a.C.) se produjo debido a los conflictos internos de Persia luego de la muerte del rey Darío. Al canalizar contra los griegos las disputas intestinas, el rey Jerjes invadió ciudades como Termópilas, Beocia y Ática. Ellas sucumbieron a la invasión persa; pero gracias a la alianza entre otras ciudades griegas que no fueron invadidas se logró contener la expansión de los persas hacia la península del Peloponeso.

Con la Tercera Guerra Médica (478 a.C.-449 a.C.), los pueblos de la Hélade se reunieron bajo el liderazgo de Atenas para expulsar de todas las ciudades helenas a los persas. Se firmó el tratado de 449 a.C., en el que los persas reconocieron la independencia de las colonias helenas de Asia menor y la soberanía de Atenas sobre el mar Egeo. Fue en ese momento cuando se creó la liga de Delos, capitaneada, precisamente, por Atenas.

El problema fue que la unidad griega se disipó: paulatinamente los griegos formaron bloques de influencia. Las dos grandes potencias, es decir, Esparta y Atenas polarizaron a las ciudades helénicas. Esparta integró a sus aliados en la liga del Peloponeso, en tanto que, como ya dijimos, Atenas reunió a sus aliados en la liga de Delos. Vino el enfrentamiento bélico. Como dice Tucídides (1972: 49) en su libro Historia de la guerra del Peloponeso (431 a.C.-404 a.C.): "Lo que hizo a la guerra inevitable fue el creciente poder de Atenas y el miedo que este poderío causó a Esparta”. Conviene señalar que Isócrates nació poco antes de que esta guerra estallara. Los recuerdos de su niñez y juventud le dejaron huellas indelebles.

Como dice Robert Hariman (2004: 225-226): “Isócrates vivió en un período en el que Atenas sufrió derrotas militares y la ocupación, la pérdida del imperio, la tiranía y represalias contra la ciudad, la degradación de los valores de la ciudad, explotación económica y turbulencia social... El reto era, entonces, garantizar la continuidad cultural".

El propósito de Isócrates fue que su patria recuperara la grandeza mediante el mayor poder que la había distinguido desde su creación, la cultura. Gorgias, su maestro, cultivó en su discípulo ese ideal (The New Encyclopaedia 
Britannica, 2007: 416-417). Otros de los grandes maestros griegos que contribuyeron a la formación de Isócrates fueron Pródico y, ni más ni menos, su casi homónimo, Sócrates (Raubitschek, 1992: 319-320). De hecho, a Isócrates se le considera el más grande maestro de oratoria de la Antigüedad. Cicerón, por ejemplo, retomó su método y lo aplicó a Roma.

Durante la Guerra del Peloponeso, Isócrates perdió su fortuna y se ganó la vida escribiendo discursos jurídicos que otras personas leían en los tribunales. Trató de iniciarse como orador; pero la falta de voz y la timidez lo disuadieron de continuar por esa vía. Entonces decidió seguir la carrera magisterial.

Entre sus alumnos sobresale Timoteo, prominente general, Nicocles, rey de Salamina y Chipre, y dos grandes historiadores: Ephorus, quien escribió una historia universal, y Theopompus, quien escribió una historia de Filipo II de Macedonia.

Discursos y escritos suyos como el Panegírico (380 a.C.), Nicocles (372 a.C.), Sobre la Paz (355 a.C.), Areopagitico (354 a.C.), y el Panatinaicos (339) son testimonio de los acontecimiento de aquella época. No obstante, lo que nos interesa aquí es abordar esos escritos desde el punto de vista de la filosofía política con especial referencia a la educación cívica. Es importante conocer las vicisitudes históricas que propiciaron esos escritos. No obstante, para nosotros es aún más relevante destacar la actualidad de las tesis filosóficas y educativas de Isócrates.

De los dos grandes apartados en que podemos dividir su pensamiento, vale decir, el conocimiento de la democracia ateniense y el ideal del panhelenismo, algunos estudiosos han puesto más atención en el primer tema señalando que su obra fundamental es Areopagítico. Allí presenta el funcionamiento de las instituciones de esa ciudad-Estado, en especial el Areópago, cuerpo colegiado que ejercía una vigilancia y control sobre la ciudad. Otros estudiosos, en cambio, se muestran más interesados en el panhelenismo. En este caso, el documento insigne es Panegírico, que es una convocatoria a la hermandad de los pueblos griegos.

\section{Isócrates y la democracia}

En nuestra opinión Isócrates es el padre de la educación cívica y, en especial, de la educación cívica que nutre a la democracia. La tesis fundamental que recorre todo el pensamiento democrático desde la Antigüedad hasta nuestros días es que los ciudadanos tienen más importancia que los gobernantes. Pues bien, como ejemplo de su apego a la democracia podemos citar una carta escrita en 359 a.C en la que nuestro autor afirma: "La vida de un hombre común y 
corriente es mejor que la vida de un rey, y honrar a un estado libre es más dulce que honrar a una monarquía" (Isócrates, 1928: XXXVIII). No obstante, debemos precisar lo que para él significaba la "democracia." Como ha quedado señalado, su ideal fue la democracia de Solón y Clístenes.

¿En qué consistió la democracia de Solón y Clístenes? Aristóteles, en su libro Constitución de los atenienses, señala que la sabiduría de Solón radicó en que pudo conciliar los intereses de los nobles y el pueblo. Sobre todo, descargó al pueblo de deudas mediante "la liberación de cargas" (Aristóteles, 2005: 35). También reordenó de una manera hábil al régimen político al equilibrar el "Arcontado" con el "Areópago", (Aristóteles, 2005: 37-51). Respecto a Clístenes, Aristóteles observa que llevó a cabo reformas más profundas que Solón "con su mira puesta en la masa popular" (Aristóteles, 2005: 71).

Vale la pena destacar que en su libro Política, Aristóteles dedica un apartado específico a Solón. De él dice:

En cuanto a Solón, algunos creen que fue un legislador respetable: abolió la oligarquía por ser demasiado absoluta, terminó con la esclavitud del pueblo y estableció la democracia tradicional, mezclando bien los elementos de la constitución, pues el Consejo del Areópago era un elemento oligárquico, las magistraturas electivas, aristocrático, y los tribunales, democrático. Parece que Solón no abolió las instituciones que antes existían, el Consejo y la elección de los magistrados, sino que estableció la democracia al hacer que todos los ciudadanos formasen parte de los tribunales. Por eso, precisamente, algunos le reprochan haber anulado el otro elemento al hacer al tribunal, designado por sorteo, dueño soberano de todas las decisiones (Aristóteles, 2008: 144-145).

Isócrates marcó distancia entre el ideal democrático y la realidad que le tocó vivir: si bien reafirmaba su fe en la democracia ateniense como había sido fincada por Solón y Clístenes, miraba al Estado ateniense de sus días con desdén, pues le parecía que se trata de una degradación (Isócrates, 1928: XXVIII-XXIX).

¿Cuál era la tarea por emprender? La respuesta es inequívoca: se debía retomar el modelo primigenio. Su contribución radicó, precisamente, en recordar la gloria del antiguo estado ateniense y su capacidad para encabezar a las ciudades griegas tanto en el campo cultural como en el campo políticomilitar. Había que echar mano de la educación. Con justa razón en las primeras páginas de la Introducción General de la edición en inglés de sus obras se lee: "El objeto primero de su instrucción es formar correctamente al hombre y al ciudadano" (Isócrates, 1928: XXV).

La educación del hombre y del ciudadano para rehabilitar la vida pública. Pero ¿cómo educar? Esa era la pregunta clave. Isócrates se dio cuenta de que "la democracia es ante todo una forma de discurso que no puede ser monopolizado 
por alguna persona en específico. Ese discurso sólo puede ser aprendido en medio de muchas voces" (Hariman, 2004: 227). En efecto, en las tiranías una sola persona habla y las demás callan; en las democracias todos los hombres hablan y todos escuchan.

Ciertamente, la democracia ateniense tuvo instituciones y líderes sobresalientes: "Los estadistas que hicieron grande a esta ciudad no eran gente de la calaña de los actuales demagogos y agitadores. Fueron hombres de elevada cultura y espíritu superior los que expulsaron a los tiranos e instauraron la democracia y lo que luego vencieron a los bárbaros y unificaron a los griegos liberados bajo la dirección de Atenas” (Jaeger, 2002: 948). Convenía tener en mente a los grandes hombres y ciudadanos virtuosos de antaño; saber que si ellos pudieron salir adelante, también sus descendientes lo podían hacer.

Conviene mencionar que los demagogos y agitadores quedaron bien descritos en comedias como la de Aristófanes, "Los Caballeros". Allí se desarrolla una larga discusión entre el Morcillero y Paflagonio para convencer a Demo (el pueblo) acerca de quién de entre ellos puede ser el mejor líder. Previamente a esta discusión hay un diálogo entre el Morcillero y otro personaje, Demóstenes, en el que el primero le pregunta al segundo: "Pero me pregunto ¿cómo seré yo capaz de gobernar al pueblo?” El segundo responde:

Eso es tarea facilísima. Haz cabalmente lo que haces. Revuelve todos los asuntos, hazlos morcilla y congráciate siempre con el pueblo endulzándole con frasecillas de cocinero. Las demás condiciones del liderazgo las reúnes: lenguaje indecente, ruin linaje, eres discutidor. Tienes todo lo necesario para la política (Aristófanes, 2008: 259-260).

Para evitar la degeneración de la democracia, Atenas debía emprender reformas internas. No se trataba de imponer las transformaciones por medio de la fuerza, tal cosa, además de indeseable, era imposible. La alternativa era la persuasión por medio del intercambio de ideas.

Isócrates comprendió que el motor de la política democrática son los cambios graduales. A su vez, las transformaciones por pasos sucesivos requieren a la educación como elemento que nutre a la inteligencia. Y la educación, por su parte, se nutre de dos fuentes, la cultura y la historia: en cuanto a la historia, Isócrates se apoyó en Tucídides. Conveniente señalar aquí que a Tucídides se le considera el padre tanto de la historia como de las relaciones internacionales. Fue este pensador quien registró la oración fúnebre de Pericles en honor de los primeros caídos en la Guerra del Peloponeso y que se considera como uno de los más altos elogios a la democracia:

Tenemos una constitución que no trata de imitar las leyes de las ciudades vecinas, sino que es ejemplo para las demás. Nuestro gobierno se llama democracia porque la administración no pertenece a pocos sino a muchos. Por esto cada uno de nosotros, in- 
dependientemente de su condición, está obligado a procurar el bien y honrar a la ciudad. Cada cual puede ser nombrado para ejercer cualquier cargo, no por su linaje o riqueza, sino por su virtud y bondad. Por pobre que sea, con tal de que pueda hacer bien y provecho, no será excluido de los cargos y dignidades. Por lo que respecta al Estado nos gobernamos libremente. Los tratos y asuntos que realizamos cotidianamente con otras personas los hacemos sin causar molestias; sin dañarnos ejercemos recíprocamente los relaciones privadas; en la vida pública el respeto nos impide violar las leyes (Thucydides, 1972: 83-84).

La educación cívica consistía en enseñar los valores resaltados por Pericles en esta oración fúnebre: el compromiso con la comunidad política; la selección de los representantes y funcionarios independientemente de la condición social o del rango al que pertenecieran; la libertad como participación en los asuntos públicos; el sometimiento de todos a la ley. Para Isócrates estos elementos no debían sólo rehabilitar a Atenas; por el contrario, debía extenderse a toda Grecia. A su entender, educación cívica y panhelenismo caminaban de la mano: "La educación de Isócrates se dirige a toda la polis y aspira a estimularla a la realización de actos que la hagan feliz a ella misma y rediman a los demás griegos de sus dolores" (Jaeger, 2002: 927).

\section{Admonición a los atenienses}

En el Areopagitico, Isócrates sostuvo que los atenienses hacían mal al sentirse poderosos porque tenían embarcaciones y ejércitos sin percatarse de que no tenían el respaldo de las ciudades-Estado de Grecia. Es decir, tenían la fuerza pero no el consenso. Por eso, trata de persuadir a sus conciudadanos sobre lo errado de esa posición. Los atenienses debían recapacitar. Ya no eran los tiempos en los que la democracia imperaba como una forma de gobierno bien dirigida; la corrupción y disolución de las costumbres habían carcomido su régimen político. Era conveniente corregir lo que se habían hecho mal. Ya no podían presentarse como ejemplo para los demás pueblos de Grecia; primero había que retomar las bases de la democracia.

En el “Areopagítico", Isócrates (1929: 113) escribe: “Es en favor de la democracia de nuestros antepasados que yo pretendo hablar... debemos estar prestos a restaurar aquella democracia originaria que fue instituida por Solón". Se trata de la democracia que los Treinta Tiranos anularon. El problema con los tiranos es que polarizaron las relaciones sociales provocando el conflicto. La distancia entre el grueso de la población y los aristócratas se hizo aún más grande. Esto provocó conflictos y rencillas de toda índole que pusieron a la ciudad en vilo. Clístenes fue quien sacó a los tiranos del poder y rehabilitó al gobierno popular. 
La decadencia de aquella democracia ejemplar sobrevino cuando la libertad fue alterada y confundida con el libertinaje. Eso fue lo que le tocó vivir a Isócrates: ahora "se toma a la democracia como insolencia, a la libertad como desorden, a la igualdad como imprudencia en el discurso y a la felicidad como licencia para hacer lo que a cada cual le plazca" (Isócrates, 1929: 115-117). El problema es que los excesos se convierten en la norma en un régimen que cree ser democrático. Ese régimen ha perdido el primero rasgo que distingue a la verdadera democracia, la autolimitación de los ciudadanos y de los funcionarios.

En una democracia degradada, las amistades no se hacen con base en la virtud, sino en la complicidad. Por eso Isócrates (1929: 267) escribió en "Antidosis":

ellos [los malvados] odian no sólo a los mejores hombres, sino también a las acciones nobles; y, por si fuera poco, para su propia vergüenza, se alinean con los que obran mal y actúan en consonancia con ellos, en tanto que cuando tienen poder destruyen a quienes son causa de su envidia. Ellos proceden así no por ignorancia sino porque quieren infligir daño y esperan no ser descubiertos y así, protegiendo a los de su calaña, piensan que están abonando a su misma causa.

Nada de eso fue permitido en tiempos de Solón y Clístenes. Por el contrario, se detestaba y castigaba a los malhechores.

Lo que contribuyó a la buena conducción de los asuntos públicos fue el reconocimiento de dos tipos de igualdad: 1) La que hizo a todos los ciudadanos semejantes entre sí; 2) la que le dio a cada hombre lo que le correspondía. Se distribuyeron honores y castigos según el bien o el mal que hiciesen. A los que desempeñaban cargos públicos no se les dieron riquezas en demasía respecto de lo que era lo normal entre la gente común. Simplemente, se seleccionaron a los mejores hombres para desempeñar las funciones administrativas. A esos funcionarios lo que les interesaba era ganarse el aprecio de la gente.

Se consideró que esta manera de nombrar magistrados era más democrática que aquella de seleccionar con base en la elección, porque, si se procedía así, se podía dejar la puerta abierta para que se introdujese la oligarquía. Por eso escribió en el Areopagitico: "Mientras que con base en el plan de seleccionar a los hombres más dignos, el pueblo tendría en sus manos el poder de preferir a aquellos que fuesen más fieles a la constitución vigente" (Isócrates, 1929: 117-119).

Parte de la educación cívica consistía en hacer que los ciudadanos participaran en los asuntos públicos. Acostumbrarlos a no lucrar con la riqueza pública. Incluso, si hacía falta, cada quien ponía de su propia bolsa para completar los gastos colectivos. En el Areopagítico también se lee: 
En pocas palabras, nuestros antepasados resolvieron que el pueblo, como el supremo jefe del Estado, debería nombrar a los magistrados, llamar a rendir cuentas a quienes no desempeñaran bien su encargo, y resolver las disputas. En tanto que aquellos ciudadanos que tuviesen tiempo y recursos, deberían dedicarse a la atención de los asuntos públicos, como servidores del Estado, habilitados para emprender tareas gubernativas si probaban ser confiables y aptos para recibir tal honor; pero, de otra parte, podían ser castigados si procedían incorrectamente, y recibir los peores castigos si así lo ameritaban (Isócrates, 1929: 121).

Tal fue la democracia bien practicada. Como régimen político, era el sistema más estable y más justo que se pudiese encontrar. Ella confería los cargos públicos a los hombres más aptos; pero, al mismo tiempo, dejaba en manos del pueblo la autoridad suprema.

La clave estaba en que, desde niños, los atenienses estaban sujetos a un gran cuidado. De esto se encargaba el Areópago. Como hemos señalado, éste era un cuerpo colectivo compuesto de hombres de noble cuna, que habían hecho carrera en el Arcontado. Como grupo sobresalía por encima de cualquier otro consejo de la Grecia antigua. El problema para Isócrates es que el Areópago se degradó al introducir en él individuos que ya no fueron captados de conformidad con el criterio de ser los mejores ciudadanos.

Algunos autores han querido ver en la predilección de Isócrates por el Areópago un cierto elitismo (Konstan, 2004: 116-117). En contraste con esta interpretación "elitista", nos parece que la función del Areópago debe ser entendido con base en el papel que desempeñó en el conjunto de la democracia ateniense y no solamente como un "grupo de élite."

Isócrates (1929: 129-131), en el Areopagitico, resalta que los mejores ciudadanos se producen allí donde se respetan más las leyes. Pero, añade:

Las leyes escritas no es lo que hace aumentar la virtud, sino las costumbres cotidianas. La mayoría de hombres tienden a asumir las costumbres y la moral del lugar en el que fueron educados. Es más, es evidente que donde hay un gran número de leyes muy precisas, es señal de que el Estado está mal gobernado. Se dan casos de que los hombres tratan de construir diques contra la proliferación del delito expidiendo una gran cantidad de normas. Pero los hombres que están bien gobernados no necesitan llenar los pórticos con leyes escritas, sino sencillamente fijar la justicia en los espíritus. Porque los estados no se gobiernan por decreto, sino inculcando buenas costumbres, y quienes han sido mal educados se atreverán a transgredir las leyes que han sido puntualmente elaboradas. En contraste, los hombres que han sido bien educados estarán dispuestos a respetar incluso los códigos más simples.

Los gobernantes eran quienes debían poner el ejemplo de rectitud. La honestidad como signo característico de los funcionarios era tan importante para Isócrates que la situaba como fundamento del buen gobierno: 
El criterio del buen gobierno para Isócrates no fue el del gobierno de las leyes, como tampoco lo fue el control popular sobre los órganos del Estado. Su visión se mueve más allá de la moderna concepción del Estado constitucional, o según se dice en español, el Estado de derecho, en el que la totalidad de la gestión del poder público está sujeta a la ley y a la justicia [derecho]. El punto de vista moderno efectivamente proporciona la base para una evaluación positiva de las monarquías y las aristocracias, en la medida en que respeten los derechos civiles. Pero ésta no era la posición de Isócrates. En lugar de la ley y los derechos, Isócrates presenta como criterio de excelencia política el carácter moral del gobierno (Konstan, 2004: 116).

Para cumplir con la ordenanza del buen gobierno, la ciudad fue dividida en distritos, barrios y fracciones de tal manera que pudiese haber un contacto directo entre las autoridades y la población. Quien obraba mal, era llevado inmediatamente ante el Consejo para amonestarlo o castigarlo. El propósito era mantener las buenas costumbres para que los jóvenes no cayeran en el vicio. Se les debía tener ocupados, inculcarles la sobriedad. Para Isócrates era muy importante que la juventud se vinculara a la cultura:

Si fuese realmente cierto que la cultura corrompe a la juventud, como sostiene la acusación ficticia y como tantas veces se había manifestado desde el proceso contra Sócrates, no había más remedio que extirparla. Pero si, por el contrario, es algo saludable, deberá dejarse de calumniar a sus representantes y de castigar a los sicofantes, aconsejando a la juventud que se consagre a la cultura con mayor pasión que a ningún otro interés en el mundo.

Isócrates da por sentado que toda educación espiritual superior se basa en desarrollar la capacidad de los hombres para comprenderse mutuamente. Este tipo de educación no consiste en la acumulación de simples conocimientos profesionales de cualquier clase que ellos sean, sino que versa sobre las fuerzas que mantienen en cohesión la comunidad humana. Estas fuerzas son las que se resumen en la palabra logos. La cultura superior es la que educa al hombre por el lenguaje así concebido, es decir, por el lenguaje como palabra pletórica de sentido, referida a los asuntos que son fundamentales para la vida de la comunidad humana y que los griegos llamaban "los asuntos de la polis". El hombre, como un ser compuesto del alma y cuerpo, necesita que se vele por él en este doble sentido, que es por lo que las generaciones anteriores han creado la dualidad de la gimnasia y la formulación del espíritu (Jaeger, 2002: 935-936).

Es preciso señalar, al respecto, que los atenienses ponían atención en la formación completa de las personas. De hecho, usaban la palabra kalokagathía para indicar el ideal de la educación. Dicho término abarca cualidades físicas y espirituales: perfección corporal, destreza, habilidad, sentido del honor y de la propia dignidad, solvencia económica, piedad, moderación, capacidad de juicio y sabiduría. 
Estos ideales, desgraciadamente, se pervirtieron. La degradación arrastró casi a todos. Los alejó de la cultura. Dilapidaron sus fuerzas en la embriaguez, el juego y los apetitos sensuales. Igualmente, los distanció de la política como compromiso con la colectividad; pero los acercó a la política entendida como negocio personal. Esa degeneración se debió también a quienes anularon la fuerza del Areópago. En efecto, las reformas introducidas por Efialtes en 462 a. C. desvirtuaron aquella institución. Mientras el Consejo del Areópago tuvo poder, la ciudad no estuvo llena de procesos ni acusaciones entre particulares. Tampoco hubo pobreza ni guerras. Los atenienses se ganaron la buena voluntad de los otros pueblos griegos y les inspiraron temor a los bárbaros.

Isócrates les dijo a los atenienses que sus antepasados fueron afortunados en haber podido tener una constitución como la democrática. Pero ahora les incomodaba ese recuerdo.

Una persona como Isócrates resultaba perjudicial para el status quo: sus enemigos (demagogos y sofistas) lo acusaron de pretender instaurar en Atenas una oligarquía. Pero la acusación no tenía sustento: el propio Isócrates mostró como prueba a su favor que él había criticado a las oligarquías y a los regímenes violentos mientras alababa a los sistemas basados en la justicia y la razón, esto es, los sistemas democráticos. Y, haciendo una comparación en el Areopagítico, entre la democracia y la oligarquía señaló: "Si escudriñamos en la historia de las más ilustres y grandes de las otras ciudades griegas, encontraremos que las formas de gobierno democráticas son más convenientes que las oligarquías" (Isócrates, 1929: 143).

En las oligarquías, además de que unos pocos oprimen a la mayoría, los gobernantes se someten a los enemigos de la ciudad; en cambio, en las democracias, nadie oprime a nadie, todos forman parte del gobierno y, además, ese régimen no se doblega frente a los extranjeros (Isócrates, 1929: 149).

Luego entonces, era preciso recuperar a la democracia en su forma primigenia: "Si cambiamos la constitución política, está claro que, según el mismo razonamiento, nuestra situación será parecida a la de los antepasados. Porque es forzoso que de idénticas instituciones políticas deriven siempre resultados semejantes e iguales" (Isócrates, 1929: 155). Una vez recuperada la democracia verdadera, los demás pueblos griegos se plegarían al poder de Atenas, en tanto que los bárbaros no se atreverían a atacar a Grecia. La democracia implica riqueza bien repartida. Los primeros indicios de una democracia degradada es la desigualdad en la distribución del ingreso; es decir, la polarización entre ricos y pobres. 
La pobreza envilece al pueblo. Lo transforma en una masa vulnerable. Esa masa empobrecida y sumida en la ignorancia es proclive a ser manipulada por los demagogos; esos charlatanes hacen leva de ella diciéndole lo que quiere oír, no lo que debe escuchar. Son los "lobos con piel de oveja" que al final terminan sojuzgando al mismo pueblo que los elevó al poder. La masa fanatizada es propensa a la manipulación de hombres sin escrúpulos, quienes más que pensar en el bien colectivo procuran el lucro político. A esa masa no le interesa la dirección de los hombres honestos. Como cuerpo fanatizado, fácilmente cae en la tiranía. Atenas tenía un claro antecedente de este régimen en las tres tiranías de Pisístrato (607-527 a.C.). Era, pues, necesario evitar ese riesgo: la educación era el mejor antídoto para evitar la degeneración de la democracia.

\section{La madre de la civilización}

En su libro Panegírico, Isócrates afirma que Atenas es la madre de la civilización. Por este motivo ella está llamada a encabezar la batalla contra la barbarie. La empresa era enteramente practicable. Los persas, al decir de Isócrates, eran un pueblo débil, sin genio o fuerza para la guerra; ellos prosperaron por culpa de los griegos. En su consideración, el avance contra los persas es "una misión sagrada” (Isócrates, 1928: 118).

Isócrates muestra y analiza las condiciones en que se encuentran las ciudades que polarizan la Hélade: de un lado están los espartanos; por otro, los atenienses. ¿Qué los distingue? Los espartanos privilegiaban la fuerza física; los atenienses daban más importancia a la capacidad intelectual. Compara ambos poderes con una metáfora:

Si todos los atletas adquiriesen el doble de capacidad física que en este momento poseen, el resto del mundo no sería mejor; pero dejemos que un solo hombre obtenga sabiduría y todos los hombres cosecharán los beneficios porque estarán dispuestos a compartir tal conocimiento (Isócrates, 1928: 121).

Era importante que la sabiduría emanada de Atenas fuese de nuevo compartida por los helenos como fuerza unificadora de la Hélade.

El problema del panhelenismo no se jugaba tan sólo en lo que hoy se podría llamar el terreno de "las relaciones internacionales", sino a nivel interno, precisamente, en el seno de las ciudades-Estado. Cada potencia trataba de intervenir en la política interior de los Estados dominados por la otra potencia, promoviendo el sistema propio. Así es como debe interpretarse el siguiente pasaje del Panegírico: 
Porque los pueblos helenos, una parte está sujeto, algunos a nosotros, otros a los lacedemonios, la política con base en la cual ellos gobiernan sus Estados han dividido a la mayoría de ellos. Si algún hombre, por consiguiente, piensa que antes que él traiga a los Estados capitaneados a relaciones fraternales, el resto se unirá haciendo cualquier cosa bien, él está siendo muy simplista y sin tacto respecto de la actual situación (Isócrates, 1928: 129).

Dicho de otro modo: el de los griegos no es un liderazgo que se pueda compartir entre Esparta y Atenas. Debe haber una sola cabeza. Las dos ciudades son diametralmente opuestas: tienen concepciones distintas del poder. Mientras siga prevaleciendo Esparta dominará la fuerza, el conflicto y la oligarquía. Lo único que puede integrar a los griegos es la inteligencia, la democracia y la concordia encarnadas por Atenas.

El verdadero enemigo no son otros griegos como creen los espartanos, sino los persas. Los espartanos son cortos de vista. Por esta razón Atenas debe reclamar para sí la "hegemonía”. Isócrates usa el concepto "hegemonía” (Panegírico y Antidosis), en el sentido literal del término, es decir, como supremacía: "Acaso todo debe ser hecho de manera tal que se vea que como en los pasados tiempos Atenas, justamente, asumió la soberanía de los mares. De la misma manera ahora ella reclama, no injustamente, el legado de la hegemonía" (Isócrates, 1928: 131; 1929: 219).

¿Cuáles eran las razones que asistían a Atenas para buscar esa hegemonía? En primer lugar la experiencia y las victorias obtenidas tanto en tierra como en mar. Dice Isócrates (1928: 131-133), los vaivenes de la fortuna cambian a menudo (el dominio nunca queda en las mismas manos)

y quien piensa que la hegemonía, como cualquier otra cosa preciada debe quedar en quien primero ganó ese honor, o para quienes han brindado los más altos servicios a los griegos, considero que todo esto está de nuestro lado. Si miramos al pasado podremos ver que ambos títulos de liderazgo, de acuerdo con los argumentos expuestos, responden a nuestros reclamos. Porque es sabido que nuestra ciudad es la más antigua y la más grande en el mundo, y, ante los ojos de los hombres, la más renombrada.

Si se tomase en cuenta el linaje y la experiencia, desde luego Atenas resultaría la más aventajada de las ciudades:

Los pueblos helénicos vivían sin leyes y en moradas dispersas, algunos oprimidos por los tiranos, otros muriendo en medio de la anarquía; pero Atenas los liberó de estos males tomando a algunos bajo su protección y a otros los puso en orden brindándoles su propio ejemplo. Y esto sucedió porque ella fue la primera en establecer leyes y un sistema de gobierno (Isócrates 1928: 141; Thucydides, 1972: 4).

Con esas argumentaciones Isócrates reclamaba para su ciudad la preeminencia sobre las demás comunidades de la Hélade; pero no para oprimirlas, sino para liberarlas. 
Para Isócrates, la educación, el conocimiento y la filosofía constituían los cimientos sobre los cuales se levantaban las instituciones políticas y las leyes de Atenas. Esos mismos elementos habían formado a los atenienses en los asuntos públicos haciéndolos gentiles unos respecto de otros. Eso los había salvado del infortunio y la ignorancia. Escribe en el Panegírico:

La filosofía fue dada al mundo por nuestra ciudad. Y Atenas ha honrado la elocuencia que todos los hombres anhelan y envidian a quienes la poseen, porque este es el primer don de nuestra naturaleza que nos distingue de todas las creaturas vivientes y es lo que nos eleva por encima de todos los demás. La filosofía vio que en otras actividades los azares de la vida son caprichosos tanto así que con frecuencia el sabio fracasa y el tonto tiene éxito, en tanto que los bellos y artísticos discursos jamás son cosa de hombres ordinarios, sino que son trabajo de una mente cultivada. Es aquí donde se puede ver mejor el contraste entre el culto y el ignorante (Isócrates, 1928: 149).

El rasero que Isócrates utiliza para medir el talante de los hombres no es el de la riqueza o el de la fuerza, sino el de la cultura (a la que resumía en el concepto "filosofía”):

Ella, la filosofía, sabía que si los hombres eran educados con liberalidad desde sus primeros años eso no debía ser determinado por su ánimo o su riqueza o por ventajas semejantes, sino que era manifiesto que debía ser realizado particularmente por su discurso. Y esto probó ser el mejor signo de cultura para cada uno de nosotros, y aquellos que están capacitados para la exposición de ideas no sólo son hombres de poder en sus propias ciudades sino que son objeto de veneración en otras ciudades. Y nuestra ciudad ha tomado tal distancia del resto del mundo en pensamiento y en discurso que sus alumnos se han vuelto maestros del resto del mundo. Ello ha propiciado que el nombre "griegos" ya no sea referido a una raza sino a una inteligencia, y que el título "helenos" se aplique más bien a quienes comparten una cultura que a quienes comparten una sangre común (Isócrates, 1928: 149).

En otro fragmento del Panegírico, Isócrates (1928: 167-169) expresa que las disputas entre bandos opuestos en una comunidad política debían ser de tal índole que no estuviesen diseñadas para que una de las fracciones dominase o destruyese a la otra, menos aún para que terminase imponiendo su mandato sobre el resto. Más bien las disputas deberían dar lugar a que todos sacasen ventaja para bien del Estado. Así, los círculos políticos debían organizarse no para sacar provecho personal o grupal, sino que debían ser para beneficio del pueblo:

En el mismo sentido los atenienses gobernaron sus relaciones con otros Estados. Trataron a los griegos con consideración y no con insolencia. Asumieron la tarea de encabezar a los helenos en el campo de batalla como una responsabilidad, de ninguna manera para tiranizarlos. Desearon ser tomados más como líderes que como amos, y ser considerados como salvadores que como destructores. Ellos ganaron el aprecio de las ciudades griegas 
siendo amables con ellas en lugar de aplicar la fuerza contra ellas, manteniendo la palabra dada con más honorabilidad de la que hoy lo hacen los hombres que juran respetar su palabra... y los atenienses consideraban a Grecia como su patria común.

Bajo ese espíritu se debía reconstruir el panhelenismo. Estas cavilaciones hacen decir a Isócrates (1928: 169):

En razón de que ellos [los atenienses] fueron inspirados por estos sentimientos, y educados desde pequeños en estos hábitos de conducta, ellos produjeron en las personas de aquellos que pelearon contra las hordas asiáticas tal valor que nadie, ni los poetas ni los sofistas, ha sido capaz de hablar de una manera acertada y generosa acerca de sus hazañas.

Lo que Isócrates (1928: 175) exalta de los atenienses es la lección de arrojo que dejaron como legado a las generaciones futuras:

lo que nuestros ancestros desearon sobre todo tener en alto es la reputación que ganaron. Hacerle ver al mundo que en las batallas que combatieron ellos ganaron gracias al valor y no al azar, y en segundo lugar, incitar a los griegos a llevar adelante la guerra con sus barcos, demostrando que al luchar en el mar no menos que en tierra el valor es más importante que el número.

Era una valentía inspirada en el amor a Atenas más que en el odio a los enemigos. Abundando en lo que podríamos llamar "la política exterior" concebida por Isócrates, vemos que en su discurso sobre $L a$ Paz muestra la necesidad de que el código moral sea la base de esa política. Tal discurso fue expuesto ante los atenienses a los que critica (como ya lo había hecho en los otros discursos) por aceptar y reconocer sólo a aquellos oradores que les endulzan el oído.

Con todo y ese inconveniente, Isócrates (1929: 17) no desiste de decir la verdad:

Porque yo he venido ante ustedes, no para buscar sus favores tampoco para solicitar su voto, sino para hacer saber mis puntos de vista... porque no es la buena voluntad la que ha prevalecido en asuntos que incumben a la paz, a menos que nosotros seamos bien aconsejados respecto de lo que debe ser hecho.

La cuestión es encontrar los justos términos para cada una de las partes. Y no se actúa justamente cuando se retiene por la fuerza las posesiones y los territorios de otros pueblos. Isócrates piensa que Atenas no tendrá una frontera segura en tanto no recupere la estima de los demás pueblos de la Hélade.

El problema es que la guerra hizo a los atenienses más pobres y encarar mayores peligros; las contiendas bélicas los han llevado a tener un mal nombre entre los griegos. Pero si los atenienses optasen por una diplomacia que procurase la paz tomarían el camino de la seguridad, se librarían de la violencia, la incerteza y los tumultos internos. Avanzarían en la prosperidad. 
Se librarían de los impuestos de guerra; desecharían el miedo a cultivar sus tierras y navegar con seguridad en los mares; reemprenderían actividades que se habían visto forzados a abandonar por la guerra.

Y lo más importante, tendríamos a toda la humanidad como nuestra aliada -aliados que no habrían sido forzados sino más bien persuadidos de permanecer junto a nosotros. Ellos que no aceptarán nuestra amistad con base en nuestro poder que, estamos seguros, abandonarán cuando estemos en peligro, sino que estarán dispuestos a continuar apoyándonos cuando se tiene a verdaderos aliados y amigos (Isócrates, 1929: 21).

Con inteligencia, Isócrates subraya en este pasaje que es mejor una política de conciliación, que una política de enfrentamiento. Como se aprecia, ya hace siglos se habló de la disyuntiva entre el uso del poder blando (softpower) y el poder duro ( hard power) o, si se prefiere, entre la diplomacia y la guerra (Nye, 2002: 222; 2004: 191). Pues bien, en las condiciones en las que se encontraba Atenas, de quiebra económica, de postración política, la ciudad era incapaz de obtener algún bien mediante el uso de las armas. En contraste, podían extraer beneficios tangibles de una prudente actividad diplomática. Lo que decía Isócrates era que mediante la política exterior fincada en la construcción de consensos se podrían lograr fronteras seguras.

\section{Consejos al Príncipe}

Aunque Isócrates era un defensor de la democracia, eso no le impidió comprender y exponer sus ideas sobre lo que debería ser un buen monarca. Tal perspectiva la expuso en su discurso a Nicocles:

Al estar por encima de los demás en rango debes superarlos en virtud... debes estar convencido de que la educación y la diligencia están en el más alto nivel de importancia para mejorar nuestra naturaleza. Rodéate de los más sabios de entre tus conciudadanos y, cuando esto no sea posible, busca a los hombres más sabios en otras ciudades... deberías oír a los poetas y aprender de los eruditos de manera que puedas enriquecer tu mente para juzgar a los que son inferiores a ti y para emular a los que son superiores a ti. De esta manera te convertirás rápidamente en el hombre que nosotros suponemos que es el adecuado para desempeñar correctamente los deberes de un rey, y para gobernar el Estado como debe ser (Isócrates, 1928: 47-49).

Pero, surge la pregunta: ¿en qué consiste no el buen gobierno, sino el buen gobernante? En esta ocasión, es decir, en Nicocles, responde:

Serás un buen líder si no permites que la multitud cometa atropellos, pero tampoco que los sufra. También debes estar atento a que los mejores de entre el pueblo sean objeto de honores, y cuida que los demás hombres no resientan ultrajes a sus derechos. Esto son los primeros y más importantes factores del buen gobierno (Isócrates, 1928: 49). 
El buen gobernante debe garantizar el orden público y hacer que los derechos de los ciudadanos sean respetados.

El consejo al Príncipe es que si las instituciones y las leyes no están bien fundamentadas, debe cambiarlas. Lo invita a hacer lo mejor por su patria, pero si no sabe cómo hacerlo debe tomar ejemplo de los Estados que han tenido éxito.

En razón de que el Príncipe tiene que ver por el bien colectivo, debe estar más educado que los demás hombres. Las personas comunes y corrientes no tienen contacto permanente con la política. En consecuencia, sus errores no son tan notables; pero sí lo son los del monarca. Isócrates (1929: 225) reconoce, en Antidosis, que las cosas suelen ser al revés: "Les reprocho a los monarcas que, se supone, ellos deben estar más preparados que los demás; sin embargo, la realidad es que muchas veces están menos educados que los hombres comunes y corrientes". En este mismo sentido, el monarca debe evitar los placeres y las disipaciones.

El secreto del buen Príncipe radica en no mostrar su autoridad a través de la fuerza. La clave está en que los súbditos reconozcan su buen juicio. El Príncipe debe estar preparado para la guerra, pero debe evitar llevar a cabo agresiones injustas. A los Estados débiles ha de tratarlos como él quisiera ser tratado por los Estados más fuertes.

El buen gobernante debe favorecer lo que hoy llamamos opinión pública: debe ser condescendiente con quienes expresan su sentir. Es mejor, dice en Nicocles, dejar fluir las voces de la gente que frenarlas: "Garantiza la libertad de expresión a quienes tienen buen juicio, para que cuando tengas duda cuentes con amigos que te ayuden a decidir" (Isócrates, 1928: 57).

De esta manera, el hombre de poder puede estar más enterado acerca de lo que piensa el pueblo y así tomar las determinaciones más certeras. Pero aquí surge un tema muy delicado porque, como dice en Antídosis, hay que distinguir la opinión espontánea de la opinión interesada; vale decir, la que brota naturalmente del pueblo de la que fabrican los agitadores y los demagogos. Es de sabios separar estos dos tipos de discurso: promover el primero y evitar el segundo. Porque uno nutre a la democracia; el otro la envenena (Isócrates, 1929: 263).

Gobernar un Estado, ciertamente, es saber gobernar las propias pasiones. Por eso Isócrates le dice a Nicocles: "Gobierna más firmemente tus deseos que como ejerces el poder sobre tu pueblo" (Isócrates, 1928: 57). Procede de tal manera que el pueblo hable, en sus casas, con admiración de tu sabiduría más que de tus defectos. Y es que la prudencia fue tomada desde un principio como una virtud política: "Pon tu propia prudencia como ejemplo para los 
demás, sabedor de que la manera de vivir de toda la ciudad concuerda con sus gobernantes" (Isócrates, 1928: 57-59).

Para los griegos, como hemos visto, el desempeño de los cargos públicos era un honor. Servir a los demás era una distinción que se le otorgaba a quienes habían mostrado una conducta virtuosa. Por eso el abuso en el ejercicio del poder era castigado no solamente por las leyes, sino también por la opinión pública. Era, pues, de la máxima importancia labrarse un buen nombre:

Considera más importante dejar a tus hijos un buen nombre que una gran riqueza, puesto que la riqueza es efímera, mientras que la fama perdura. El buen nombre quizá acarree la fortuna, pero la riqueza no puede comprar un buen nombre. La fortuna les llega incluso a hombres de poca monta, pero un buen nombre solamente puede ser adquirido por hombres de talante superior (Isócrates, 1928: 59).

En Atenas el prestigio social no lo daba la riqueza; se forjaba mediante una vida ejemplar. Esto caminaba de la mano con la moderación: "Cuida siempre tus palabras y acciones de manera que cometas los menos errores posibles. Aprovecha las oportunidades que se te presenten, desde el momento en que son difíciles de captar, opta por cuidar algo antes que extremarte" (Isócrates, 1928: 59).

Isócrates (1928: 61) hace énfasis en que el poder político es nutrido por la práctica en los cargos públicos y la cultura: "Si quieres examinar qué es lo que deben saber los reyes, sírvete de la experiencia y del estudio; porque el estudio te mostrará los caminos, y el ejercitarte en las propias acciones te dará el poder para manejar los asuntos que trates".

Va otro consejo: que el gobernante cuide su seguridad personal y procure la seguridad del Estado. Pero en caso que la vida propia vaya en prenda, es preferible morir con dignidad que vivir en el oprobio: "Pon todo tu esfuerzo en preservar tu propia persona y la seguridad de tu Estado, pero si eres empujado a arriesgar tu vida, opta por morir con dignidad en lugar de vivir en medio de la vergüenza. En todas tus acciones recuerda que eres un rey, y procura jamás hacer algo que esté por debajo de la dignidad de tu rango" (Isócrates, 1928: 61).

Con modestia se despide de Nicocles diciendo:

Haz uso de los consejos que te he dado, o bien busca otros mejores. Considera sabios no a los que disputan sobre cosas sin importancia, sino a quienes hablan con propiedad de asuntos relevantes; tampoco a los que están en apuros y que, sin embargo, prometen a otros grandes fortunas. Toma en cuenta a aquellos que reclaman para sí poco, pero que saben lidiar con las cosas de la vida al tratar con moderación tanto las venturas como las desventuras (Isócrates, 1928: 63). 


\section{Por último:}

Rechaza a los que nada saben de lo que es conveniente; pues está claro que quien no es útil ni para sí mismo, tampoco será útil para los demás... pero cuando son inteligentes y capaces de ver más allá, tómalos en cuenta y aprécialos, sabiendo que un buen consejero es lo más valioso y lo más raro de todas las posesiones... Y cree verdaderamente que eso contribuye más a tu entendimiento y a la grandeza de tu reino que cualquier otra cosa (Isócrates, 1928: 69).

Es, a fin de cuentas, el valor de la inteligencia sobre la fuerza.

\section{Conclusiones}

Isócrates dio consejos a los gobernantes: tienen que ser sensibles ante la opinión pública; dominar su carácter; rodearse de personas con buena reputación; cultivar la lectura y tener sensibilidad para encarar los problemas políticos; no dejarse llevar por las adulaciones; no caer en los extremos igualmente perniciosos del exceso ni del defecto; actuar con dignidad en vista de que es una persona pública; no permitir que la multitud cometa atropellos, pero tampoco que los sufra; respetar los derechos de las personas; dominar sus impulsos.

Pero Isócrates también dio consejos a los ciudadanos: que practiquen sus derechos y libertades para que sean reales y no se queden en simples pronunciamientos; ser parte de la koiné (la vida pública) y no quedarse arrinconados en la idia (la vida privada); actuar con base en la razón y no ser arrastrado por las pasiones; recurrir a la discusión pública y apartarse de la manipulación de los demagogos; estar prestos a la colaboración en lugar de a la destrucción. Como dice Norberto Bobbio (1986: 24):

la única manera de hacer de un súbdito un ciudadano es la de atribuirle aquellos derechos que los escritores de Derecho público del siglo pasado llamaron activae civitatis y la educación para la democracia desarrolla en el mismo sentido que la práctica democrática. De acuerdo con el modelo jacobino esto no debe ser primero, porque en primera instancia debe venir la dictadura revolucionaria y sólo después el reino de la virtud. Pero para el buen democrático esto no debe ser así, el reino de la virtud (que para Montesquieu constituía el principio de la democracia contrapuesto al miedo, principio del despotismo) es la misma democracia. La democracia no puede prescindir de la virtud, entendida como amor a la cosa pública, pues al mismo tiempo debe promoverla, alimentarla y fortalecerla.

Desafortunadamente, lo que hoy abunda son ciudadanos indiferentes, poco comprometidos con los asuntos públicos. No obstante, cuando vienen momentos de agitación, y ante la carencia de una educación cívica adecuada, esos mismos ciudadanos, indiferentes y poco instruidos se mueven, repentinamente, al extremo opuesto, al fanatismo. Son presa de los demagogos o de 
movimientos radicales que proclaman, precisamente, la dictadura revolucionaria como primer paso para arribar posteriormente a un supuesto "reino de la virtud".

Pero ya vimos en lo que terminó aquel experimento de una sociedad supuestamente mejor y más democrática: en la más grande de las antiutopías (el comunismo estalinista). Aun así, hay quienes no se resignan a aceptar esa derrota histórica y quieren exhumar la violencia política como mecanismo para alcanzar una democracia presuntamente superior.

Convengamos en que la indiferencia y el fanatismo no son compatibles con la democracia. A la indiferencia y el fanatismo les estorba la inteligencia. Una se regodea en la molicie, otra en las pasiones. El régimen democrático se construye con base en la discusión de las ideas por medios pacíficos. Efectivamente, como decía Montesquieu, la democracia es el reino de la virtud que no necesita preámbulo alguno de carácter revolucionario para construirse. Lo que la forja es el ejercicio cotidiano de la participación ciudadana.

Las aportaciones de Isócrates para la educación cívica se sintetizan en los siguientes puntos:

1. La reivindicación de la educación cívica como mecanismo para salir de la barbarie y construir una comunidad de hombres libres.

2. La educación cívica como nutriente fundamental de la democracia.

3. La educación cívica es el elemento fundamental para crear una ciudadanía fuerte.

4. Esa educación cívica se hace realidad mediante el respeto de las ideas ajenas y a través del intercambio de ideas; o sea, gracias al arte de la polémica. La razón debe dominar a las pasiones. El uso de la palabra sirve para evitar los enfrentamientos violentos.

5. Se debe educar a los individuos desde la infancia para que sepan pensar y estructurar correctamente sus ideas. Así, las podrán expresar de manera adecuada tanto de forma oral como escrita.

6. Isócrates fue maestro de la retórica como arte de la persuasión.

7. Uno de los motores de la polémica es el principio de contradicción.

El esfuerzo intelectual de Isócrates fue encomiable. Su larga vida, como hemos visto, estuvo dedicada a su patria, Atenas, y a tratar de rehacer la unidad panhelénica. Ni su ciudad-Estado, ni las demás comunidades políticas de la Hélade, merecían hundirse en la degradación de los conflictos políticos internos ni en las rivalidades entre quienes compartían una cultura común. 
La recuperación de la dignidad y la grandeza debían hacerse por medio de la instrucción del individuo y del ciudadano. Esa era la forma de inyectar vida a la alicaída democracia.

No obstante, las derrotas militares, la ocupación, la crisis económica y los conflictos sociales habían hecho mella en la unidad política ateniense. Ya no era posible decir que el bien de la ciudad redundaría en el bien de cada ciudadano, porque las fuerzas internas habían sufrido una grave disgregación. Cada grupo buscaba su propio beneficio. Aun así, como dice Takis Poulakos (1997: 106) en su libro Speaking for the Polis: "Los escritos de Isócrates ofrecen una visión, en la historia de la retórica, de la comunidad como una colectividad unificada, y acaso el último despliegue exitoso de la retórica en contra de las fuerzas que impulsan la fragmentación y la presión de las diferencias".

La fuerza de su argumentación en favor del Estado democrático llega hasta la época actual. El mensaje es claro: la democracia no es simplemente la suma de las opiniones individuales; la democracia es razón que se potencia en una voluntad colectiva. La Volonté Générale, diría Jean Jacques Rousseau (1964: 361) muchos siglos después. Por eso es que situamos a la deliberación social y política como fundamento de la democracia moderna (Fernández Santillán, 2011: 60).

Los escritos de Isócrates han superado la coyuntura histórica en la que fueron elaborados. Han llegado a nosotros con toda su capacidad propositiva. Han entrado a pleno derecho en la lista de las obras clásicas de la filosofía política. Una nueva cercanía ha nacido de la distancia. Como lo captó magistralmente Montesquieu (2010: 33-34), educación cívica y democracia caminan de la mano. Esa es la mayor lección que nos legó Isócrates.

\section{Bibliografía}

Almond, Gabriel y Verba Sidney (1989), The Civic Culture (Political Attitudes and Democracy in Five Nations), Newbury Park, California: Sage Publications.

Aristófanes (2008), Comedias, Madrid: Gredos.

Aristóteles (2005), Constitución de los atenienses, Madrid: Abada Editores.

Aristóteles (2008), Politica, Madrid: Gredos.

Bobbio, Norberto (1986), El futuro de la democracia, México: Fondo de Cultura Económica. Collier's Enciclopedia (1993), vol. 13, Nueva York: P.F. Collier Inc.

Enciclopedia Salvat (1971), tomo 7, Barcelona: Hare-Juss.

Fernández Santillán, José (2011), Filosofía politica de la democracia, México: Fontamara.

Habermas, Jürgen (1998), The Structural Transformation of the Public Sphere. (An Inquiry into a Category of Bourgeois Society), Cambridge, Massachusetts: The MIT Press. 
Hariman, Robert (2004), “Civic Education, Classical Imitation and Democratic Polity”, en Takis Poulakos y David Depew, Isocrates and Civic Education, Austin: University of Texas Press.

Isócrates (1928), vol. I, Cambridge, Massachusetts: Harvard University Press.

Isócrates (1929), vol. II, Cambridge, Massachusetts: Harvard University Press.

Jaeger, Werner (2002), Paideia, México: Fondo de Cultura Económica.

Konstan, David (2004), "Isocrates 'Republic'”, en Takis Poulakos y David Depew, Isocrates and Civic Education, Austin University of Texas Press.

Montesquieu (2010), El espiritu de las leyes, México: Porrúa.

Milton, John (2005), Areopagitica, México: Fondo de Cultura Económica.

Nye Jr., Joseph S. (2002), The Paradox of the American Power (Why the World's only Superpower Can't Go It Alone), Oxford: Oxford University Press.

Nye Jr., Joseph S. (2004), Soft Power (The Means to Seccess in World Politics), New York: Public Affairs.

Poulakos, Takis (1997), Speaking for the Polis (Isocrates' Rhetorical Education), Columbia: South Carolina Press.

Poulakos, Takis y Depew, David (2004), Isocrates and Civic Education, Austin: University of Texas Press.

Raubitschek, A. E. (1992), “Isocrates”, en Collier's Encyclopedia, vol. 13, New York: P.F. Collier, Inc.

Rousseau, J.J. (1964), “Du Contract Social” livre I, Chapitre VI, Id. OEuvres complètes III, París: Gallimard, Bibliothèque de la Pléiade.

The New Encyclopaedia Britannica (2007), Chicago: Encyclopaedia Britannica.

Thucydides (1972), History of the Peloponnesian War, New York: Penguin Books.

José Fernández Santillán. Doctor en la Historia de las ideas políticas en la Universidad de Turín, Italia, en 1983. Doctor en Ciencia Política por la Facultad de Ciencias Políticas, UNAM, 1990. Profesor del Tecnológico de Monterrey, Campus Ciudad de México en la Escuela de Educación, Humanidades y Ciencias Sociales. Profesor visitante de la Universidad de Harvard (2010). Profesor visitante de la Universidad de Georgetown (2013). Fulbright Scholar in Residence (SIR) de la Universidad de Baltimore (periodo sabático de 2015). Líneas de investigación: filosofía política, clásica y contemporánea. Publicaciones recientes: José Fernández Santillán, Política, Gobierno y Sociedad Civil, Fontamara (2012); José Fernández Santillán, La perspectiva internacional de los partidos políticos en México, Fontamara (2014); José Fernández Santillán, “Global Politics”, en Mexican Law Review (2013); Iliana Rodríguez y José Fernández Santillán [coordinadores], Sustentabilidad en México, México: Fontamara (2015).

Recepción: 10 de junio de 2015.

Aprobación: 16 de febrero de 2016. 